\title{
Honey let me tell you about this city! Honey as a biomonitor for lead distribution in urban environments
}

\author{
KATE E. SMITH AND DOMINIQUE WEIS
}

\author{
University of British Columbia
}

Presenting Author: katesmith@eoas.ubc.ca

Honey from Apis mellifera (Western honeybee) can elucidate metal distribution and source-apportionment in the hives' host environment. Metal concentrations, together with $\mathrm{Pb}$ isotopic compositions, measured in honey collected at varying resolutions and settings reveal different geochemical processes and pollution sources and events. We examined the efficacy of honey as a biomonitor in a young, small city (Vancouver, Canada), a relatively young megacity (New York City, USA), and a megacity with millennia-scale history of $\mathrm{Pb}$ use (Paris, France). On small (i.e., city) scales, metal concentrations and $\mathrm{Pb}$ isotopic compositions of honey vary geospatially as a function of land use and proximity to pollution point sources. Concentrations of elements associated with anthropogenic activities (e.g., $\mathrm{Pb}, \mathrm{Sb}$, V) are elevated in honey collected from sites nearer to the city centre. We also found that honey is suitable for tracking $\mathrm{Pb}$ fallout after an acute pollution event; for example, the April 2019 fire at Notre-Dame cathedral in Paris.

To test the biomonitoring efficacy of honey on a regional scale, we measured the $\mathrm{Pb}$ isotopic compositions of honey from eastern North America. Most notably, the $\mathrm{Pb}$ isotopes in honey reflect the different sources of $\mathrm{Pb}$ ore used throughout the twentieth century for tetraethyllead production in the USA versus in Canada. On a global scale, the $\mathrm{Pb}$ isotopic compositions of honey fall on the worldwide $\mathrm{Pb}$ array, defined by the leaded gasoline line, modern aerosols, and other consumables with associated terroir (e.g., wines, vinegars), thus $\mathrm{Pb}$ isotopic compositions of honey reflect its geographical origin. Endmembers in the global study include honey from the USA, which has the most radiogenic compositions (higher ${ }^{206} \mathrm{~Pb} /{ }^{207} \mathrm{~Pb}$, lower ${ }^{208} \mathrm{~Pb} /{ }^{206} \mathrm{~Pb}$ ), and honey from New Zealand, which has the least radiogenic isotopic compositions. Finally, we found that compared to other hive products, including bee (forager) tissue, bee pollen, and propolis, honey and bees are the most useful hive matrices for metal biomonitoring in urban centres and their surroundings. Honey is additionally advantageous because it is nonperishable and easily sampled and shipped by community scientists (e.g., hobby apiarists) around the world. This work demonstrates the important role of community science in environmental biomonitoring efforts. 